\title{
Malaria in Eritrean migrants newly arrived in seven European countries, 2011 to 2016
}

Klara Sondén ${ }^{1,2}$, Thierry Rolling ${ }^{3,4}$, Andreas Wångdahl'1,5, Elsie Ydring ${ }^{6}$, Sabine Vygen-Bonnet ${ }^{7}$, Robert Kobbe ${ }^{8}$, Johan Douhan ${ }^{1}$, Ulf Hammar9, Janneke Duijster ${ }^{10}$, Brechje de Gier ${ }^{10}$, Joanne Freedman ${ }^{11}$, Nicole Gysin ${ }^{12}$, Klaus Stark ${ }^{7}$, Flora Stevens ${ }^{11}$, Lasse Skafte Vestergaard ${ }^{13}$, Anders Tegnell ${ }^{6}$, Anna Färnert ${ }^{1,2}$

1. Department of Medicine Solna, Karolinska Institutet, Stockholm, Sweden

2. Department of Infectious Diseases, Karolinska University Hospital, Stockholm, Sweden

3. Division of Infectious Diseases, I. Department of Internal Medicine, University Medical Center Hamburg-Eppendorf, Hamburg, Germany

4. Clinical Research Department, Bernhard-Nocht-Institute for Tropical Medicine, Hamburg, Germany

5. Department of Infectious Diseases, Västmanland Hospital, Västerås, Sweden

6. Public Health Agency of Sweden, Stockholm, Sweden

7. Robert Koch Institute, Berlin, Germany

8. Department of Pediatrics, University Medical Center Hamburg-Eppendorf, Hamburg, Germany

9. Unit of Biostatistics, Department of Epidemiology, Institute for Environmental Medicine, Karolinska Institutet, Stockholm, Sweden

10. Department for Early Warning and Surveillance Center for Epidemiology and Surveillance of Infectious Diseases, National Institute for Public Health and the Environment, Bilthoven, the Netherlands

11. Public Health England, London, United Kingdom

12. Federal Office of Public Health, Bern, Switzerland

13. Statens Serum Institute, Copenhagen, Denmark

Correspondence: Klara Sondén (klara.sonden@ki.se)

Citation style for this article:

Sondén Klara, Rolling Thierry, Wångdahl Andreas, Ydring Elsie, Vygen-Bonnet Sabine, Kobbe Robert, Douhan Johan, Hammar Ulf, Duijster Janneke, de Gier Brechje, Freedman Joanne, Gysin Nicole, Stark Klaus, Stevens Flora, Vestergaard Lasse Skafte, Tegnell Anders, Färnert Anna. Malaria in Eritrean migrants newly arrived in seven European countries, 2011 to 2016. Euro Surveill. 2019;24(5):pii=1800139. https://doi.org/10.2807/1560-7917.ES.2019.24.5.1800139

Global migration has resulted in a large number of asylum applications in Europe. In 2014, clusters of Plasmodium vivax cases were reported among newly arrived Eritreans. This study aimed to assess malaria among Eritrean migrants in Europe from 2011 to 2016. We reviewed European migration numbers and malaria surveillance data for seven countries (Denmark, Germany, Netherlands, Norway, Sweden, Switzerland and the United Kingdom) which received $44,050(94.3 \%)$ of 46,730 Eritreans seeking asylum in Europe in 2014. The overall number of malaria cases, predominantly $P$. vivax, increased significantly in 2014 compared to previous years, with the largest increases in Germany (44 P. vivax cases in 2013 vs 294 in 2014, p $<0.001$ ) and Sweden (18 in 2013 vs 205 in 2014, $p<0.001)$. Overall, malaria incidence in Eritreans increased from $1-5$ to 25 cases per 1,000 , and was highest in male teenagers ( 50 cases $/ 1,000$ ). In conclusion, an exceptional increase of malaria cases occurred in Europe in 2014 and 2015, due to rising numbers of Eritreans with high incidence of $P$. vivax arriving in Europe. Our results demonstrate potential for rapid changes in imported malaria patterns, highlighting the need for improved awareness, surveillance efforts and timely healthcare in migrants.

\section{Introduction}

Between 2010 and 2013, approximately 5,200 to 5,700 cases of imported malaria were reported annually in Europe, in both travellers and migrants [1]. Most cases were caused by Plasmodium falciparum acquired in sub-Saharan Africa. Plasmodium vivax was the second most common species, accounting for approximately $10 \%$ to $25 \%$ of cases and was mainly acquired in Asia $[2,3]$. Europe saw a large increase in asylum seekers from 2013 to 2015, including people from malariaendemic countries. To what extent the patterns of imported malaria are affected by changing migration patterns has not yet been explored.

Sporadic reports of $P$. vivax cases among newly arrived Eritrean migrants were published in early 2014 [4-6] and a review of clinical records and national surveillance data in Sweden revealed a sudden increase in overall imported malaria cases, predominantly due to $P$. vivax, among newly arrived Eritreans, a group not previously noted for high numbers of imported malaria [4]. A similar increase in P. vivax cases between 2014 and 2015 was reported from Germany [5], Norway [6], the Netherlands [7], Denmark [8] and Switzerland [9]. The aim of this study was to establish the extent of malaria in Eritrean migrants in Europe in the period from 2011 to 2016. We performed an analysis of European migration data and analysed malaria surveillance data 
from the seven countries receiving the majority of Eritrean asylum applications in Europe during 2014 and 2015. In addition, we performed a retrospective review of clinical data from Germany and Sweden.

\section{Methods}

\section{Migration data}

Data on asylum applications from Eritrean citizens in 32 European countries between 2011 and 2016 were retrieved from the Eurostat database [10]. This included 28 European Union countries as well as the European Free Trade Agreement (EFTA) countries Iceland, Liechtenstein, Norway and Switzerland. In addition, weekly data on Eritrean asylum applications in Sweden from 2011 to 2016 were available at the Swedish Migration Agency in Sweden.

\section{Malaria surveillance data}

Public health agencies in the seven countries (Denmark, Germany, The Netherlands, Norway, Sweden, Switzerland, and the United Kingdom (UK)) reporting > 2000 asylum applications from Eritrean citizens in 2014 were contacted with a request for malaria surveillance data from 2011 to 2016. The requested data included overall number of malaria cases and cases among Eritrean migrants by Plasmodium species and available data on patient origin with definitions of newly arrived Eritreans described in the various countries, (Table 1). The agencies included were Statens Serum Institute (SSI) in Denmark, Robert Koch Institute (RKI) in Germany, the Centre for Infectious Disease Control at the National Institute for Public Health and the Environment in the Netherlands (RIVM), the Norwegian Institute of Public Health, the Public Health Agency of Sweden, the Federal Office of Public Health in Switzerland, and Public Health England (PHE) in the UK.

A more in-depth review was performed using surveillance and clinical data from Germany and Sweden, the two countries with the highest number of Eritrean asylum seekers.

\section{Clinical data}

In addition to surveillance data, medical records of Eritreans diagnosed with malaria at adult and paediatric hospital units in Sweden (21 hospitals in 17 of 21 counties) and Hamburg, Germany, from 2014 and 2015 were reviewed for clinical data and migration history.

\section{Ethical statement}

The clinical review was performed with permission from the Regional Ethical Review Board, Sweden (EPN 2009/1328-31/5, 2010/1080-32 and 2012/1155-32). In Germany the study was granted exemption according to local law by Ärztekammer Hamburg from requiring ethics approval because it was a retrospective analysis on anonymised patient data.

\section{Statistical analyses}

Statistical analyses were performed using Stata version 13 (StataCorp, College Station, Texas, United States). Categorical data was compared using chi-squared or Fisher's exact tests, and continuous data using Wilcoxon-Mann-Whitney test. The number of malaria cases among Eritrean asylum seekers was calculated per 1,000 Eritreans arriving in the corresponding year. All model-based comparisons were made using Poisson regressions. To compare the rate of malaria infections in different years within the group of Eritrean asylum seekers, we used the number of malaria cases among recently arrived Eritreans (as defined in the national surveillance data) as outcome and total number of recently arrived Eritreans (asylum applications) as exposure. Univariate models were used to relate different lags (0-20 weeks) of the weekly number of Eritrean asylum applications and $P$. vivax cases in Sweden from 2011 to 2016, defining the highest McFadden R-squared [11] as the strongest association for weekly number of asylum applications predicting the number of $P$. vivax cases. Haemoglobin levels were correlated with symptom duration by the Spearman correlation.

\section{Results}

\section{Migration data}

In $2014,46,730(7.1 \%)$ of the 662,165 asylum applications in Europe were submitted by Eritreans, a statistically significant increase compared to previous years (Table 1, Supplementary Figure S1 p < 0.001). Eritreans constituted the largest group of asylum applicants from sub-Saharan Africa in Europe in 2014, followed by citizens from Nigeria $(n=21,330,3.2 \%)$ and Somalia $(n=20,155,3.0 \%)(p<0.001)$.

Seven countries received 44,050 (94.3\%) of 46,730 Eritreans seeking asylum in Europe in 2014 (in descending order): Germany, Sweden, Switzerland, Netherlands, Norway, Denmark, and the UK (range: 2,275-13,255) (Table 1). The remaining 25 EU/EFTA countries reported a median of 10 applications (range: $0-820)$.

The number of Eritreans coming to Europe to seek asylum in 2015 and 2016 remained at similar levels: 47,025 (3.4\%) of $1,392,655$, and 40,260 (3.2\%) of $1,255,600$ asylum applications in Europe were from Eritrean citizens, respectively, and again mainly in the same seven countries (93.7\%). A large proportion of Eritreans seeking asylum in Europe in 2014 and 2015 were minors aged $<18$ years: $8,515(18.2 \%)$ and $12,120(25.8 \%)$, respectively (Table 1). A majority were males: in 2014 the proportion was 34,375 of $46,730(73.5 \%)$ and in 201533,055 of 47,025 (70.3\%).

\section{Total number of malaria cases}

The total number of malaria cases notified in the seven countries increased markedly in $2014(\mathrm{n}=3,771) \mathrm{com}$ pared to previous years (2011: 2,871, 2012: 2,463 and 2013: 2,731), and remained high in $2015(\mathrm{n}=3,692) . P$. 

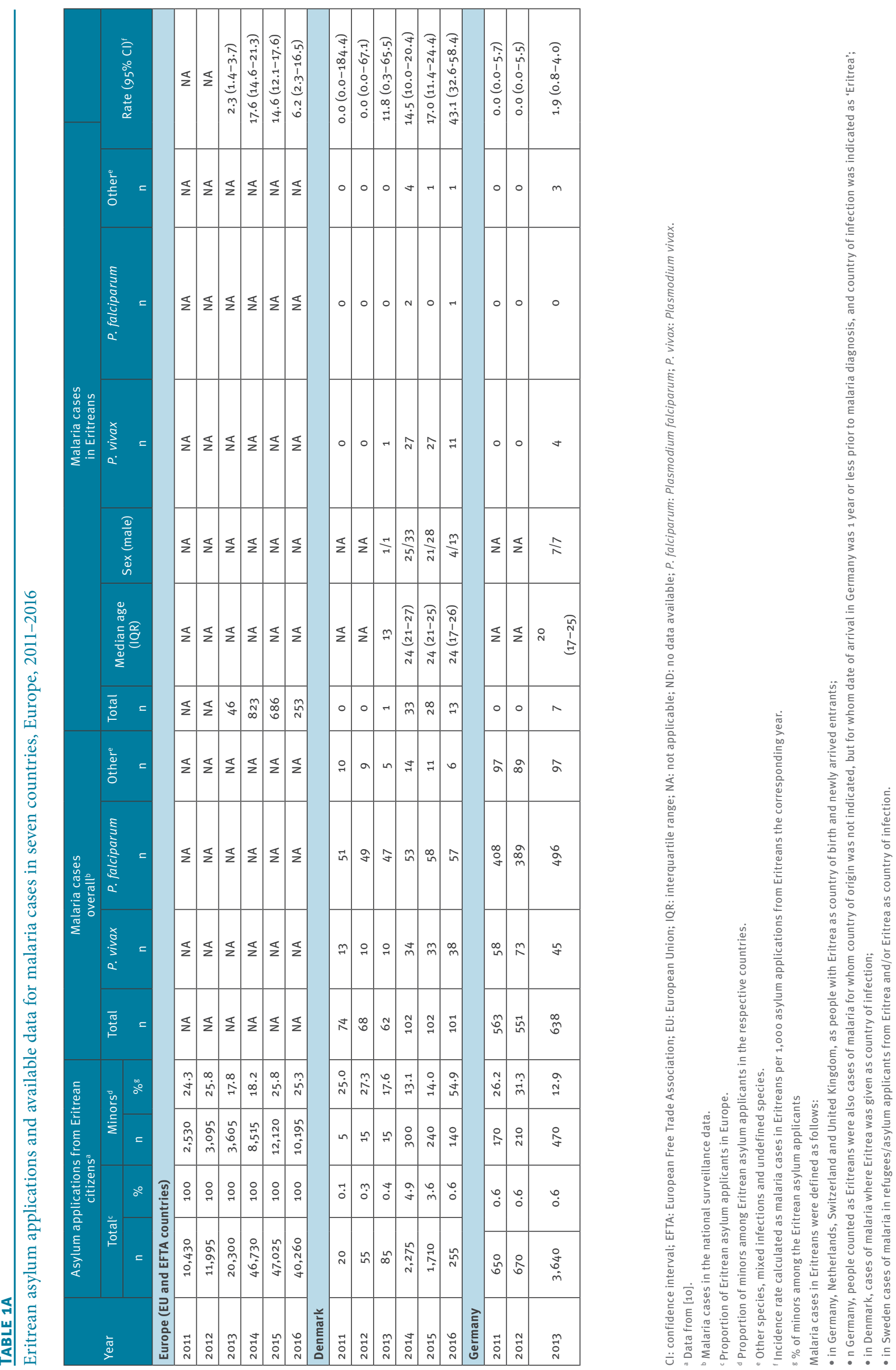

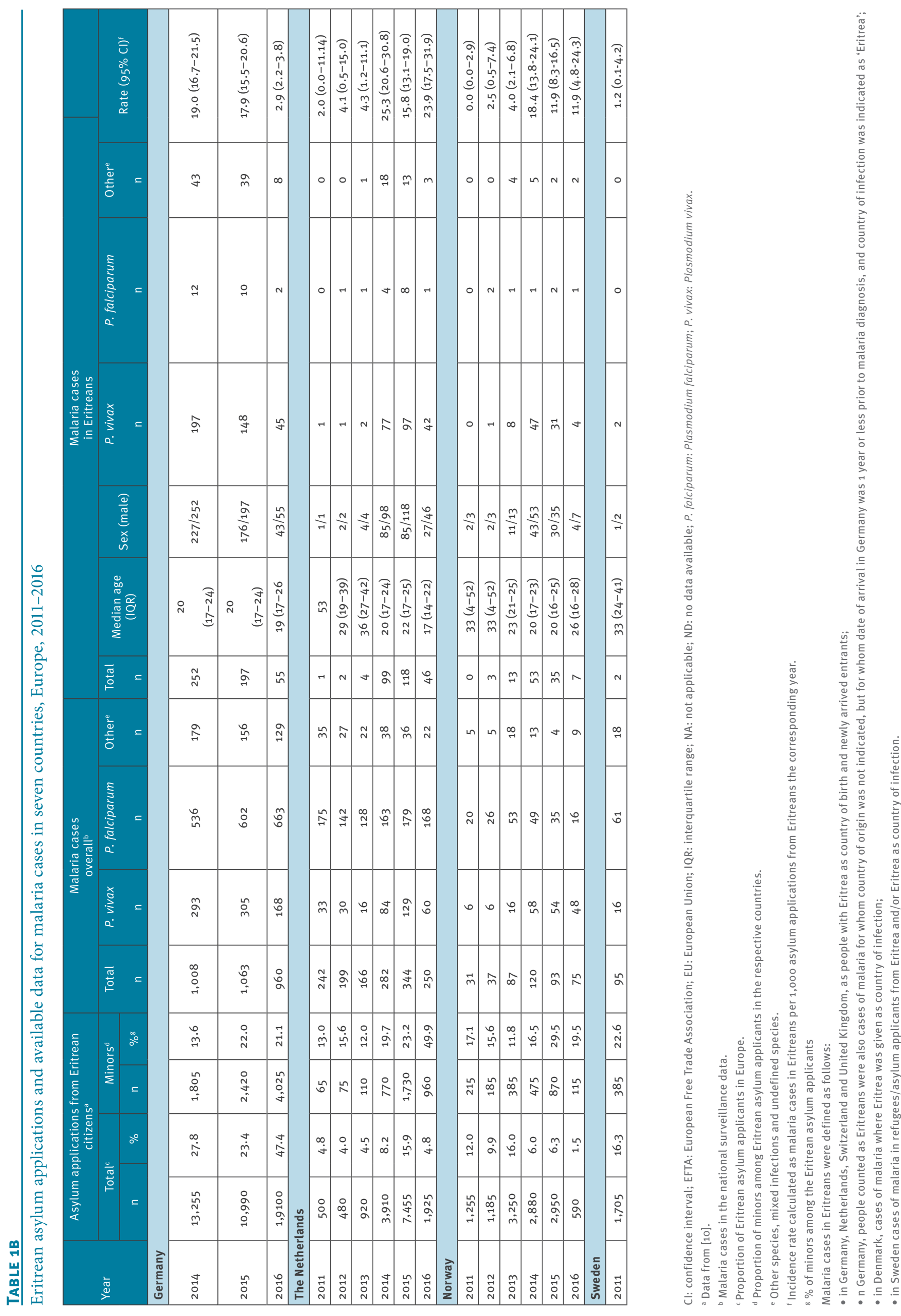

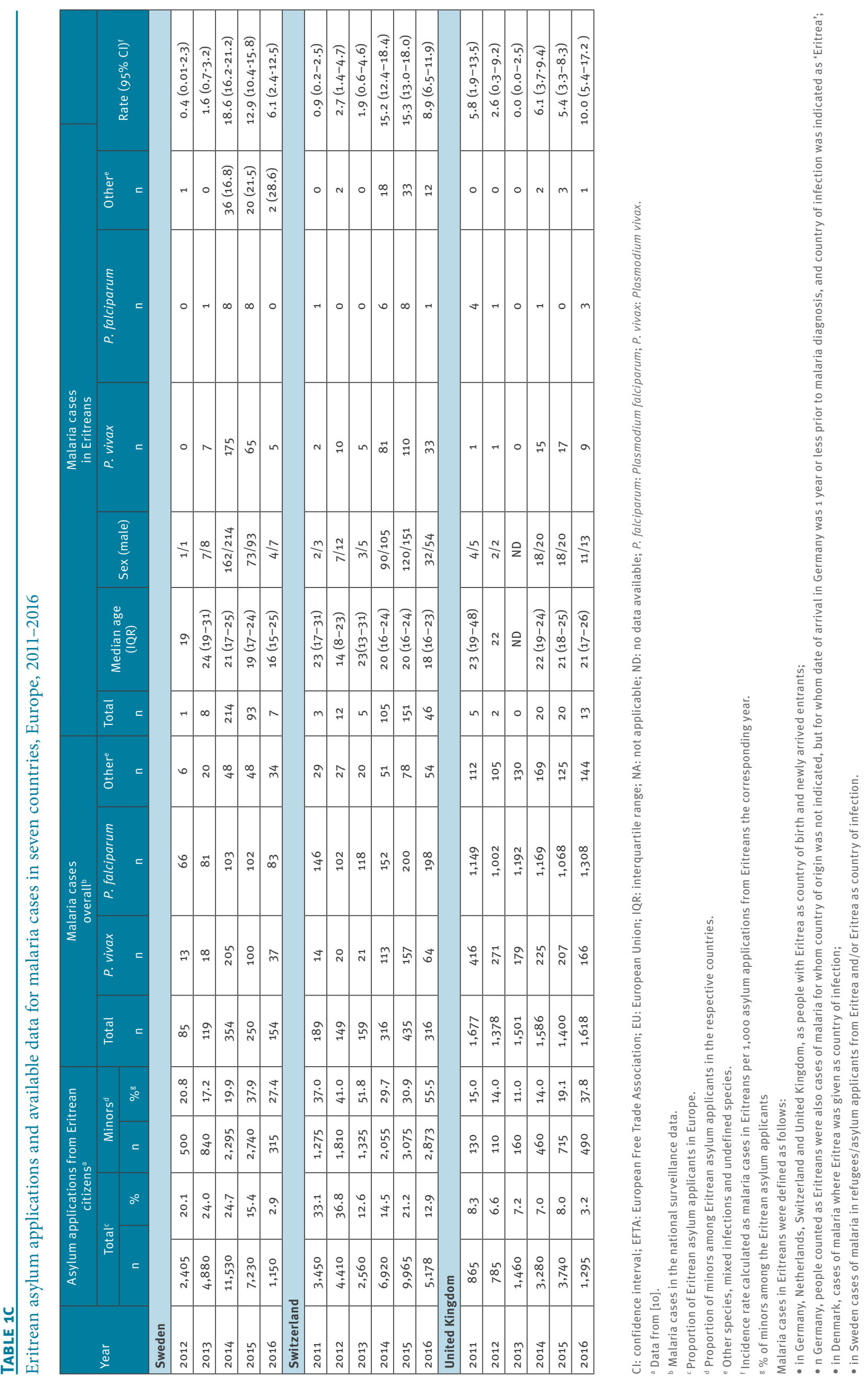
vivax was the main species accounting for the increase and the proportion of malaria cases diagnosed as $P$. vivax increased in 2014 (Table 1).

\section{Malaria cases in Eritreans}

We estimated the incidence of malaria in Eritreans per 1,000 Eritrean asylum applications in the seven respective countries. The incidence rate increased notably in $2014(18 / 1,000)$ and remained at a similar level during 2015 (15/1,000) (Table 1). During 2016, the overall incidence returned to a lower level $(6 / 1,000)$, similar to that seen from 2011 to 2013. The increase was only seen for $P$. vivax in 2014 and 2015, whereas the $P$. falciparum incidence in Eritreans remained low $(<1 / 1,000)$ between 2011 and 2016 in all countries.

The overall mean incidence from the seven countries was then used to estimate the total number of malaria cases in Eritrean asylum applicants in Europe: 47 among 20,300 Eritrean applicants in 2013, 823 among 46,730 in 2014, 686 among 47,025 in 2015, and 253 among 40,260 Eritreans in 2016 (Table 1).

\section{Germany}

Germany was the European country which received the highest number of asylum applications from Eritrea, with 13,255 in 2014, 10,990 in 2015 and 19,100 in 2016. The overall number of notified malaria cases, predominantly $P$. vivax, increased significantly in 2014 compared to previous years (44P. vivax cases in 2013 versus 294 in 2014, p<0.001). The incidence of malaria among Eritreans increased notably in 2014 with 19.0 cases per 1,000 (95\% confidence interval (CI): 16.7-21.5) and remained high in 2015 with 17.9 (95\% Cl: 15.5-20.6). Cases were predominantly in male patients with 227 of 252 (90.1\%) in 2014 and 176 of 197 (89.3\%) in 2015. The median age was 20 years in 2014 and 2015. During 2016 the incidence was similar to the period prior to 2014 (Table 1). Malaria incidence in children ( $\leq 13$ years) was o per 1,000 in 2013 and 2015, while teenagers aged 14 to 17 years had a high incidence in 2014 and 2015 (Figure 1). Year of arrival in Germany was available in the health surveillance data and $92 \%$ (95\% Cl: $89-95 \%)$ of malaria cases in Eritrean citizens in 2014 and 2015 were diagnosed in the year of arrival (Supplementary Table S2).

The clinical presentation of malaria in Eritreans was assessed by reviewing clinical records of 66 patients at the University Medical Centre Hamburg-Eppendorf during 2014 and 2015. In total, 52 of 66 patients with $I_{1} D_{10}$ code $B_{51}(P$. vivax malaria), and none of the 130 patients with ICD10 code B50 ( $P$. falciparum malaria) were Eritreans. Median age was 19 years (range: $12-52$ years) and 44 patients (84.6\%) were male. Patients reported a migration route starting in Eritrea and travelling through Ethiopia and/or Sudan, and then to Libya before crossing the Mediterranean Sea to Europe (Table 2$)$. Some 38 (73.1\%) patients reported that they had already been treated for malaria on the way to their destination country and one patient presented with severe malaria anaemia. The median symptom duration prior to contact with healthcare professionals in Hamburg was 3 days (range: 1-180) (Table 2). The proportion of $P$. vivax relapses after treatment in Germany was $7.8 \%(4 / 52)$.

\section{Sweden}

Sweden received 11,530 Eritrean asylum applications in 2014, 7,230 in 2015 and 1,150 in 2016 (Table 1). In Sweden, 119 malaria cases were reported in 2013 and 354 cases in 2014 (197\% increase, $p<0.001$ ). The increase was predominant for $P$. vivax (18 cases in 2013 versus 205 in 2014, p<0.001). The incidence among Eritreans across age groups was estimated in Sweden from 2013 to 2015 , with the highest estimated incidence in the 14-17-year age group with up to 50.7 cases per 1,000 Eritrean males (corresponding to 1 case/20 teenagers) in Sweden in 2014 (Figure 1). In 2015, the incidence in 14-17-year-olds declined, whereas it remained stable in adults.

The weekly number of $P$. vivax cases in Sweden followed the number of Eritrean asylum applications, with a time lag of 5 weeks (McFadden's R-squared: 0.31); and although the number of applications from Eritreans started to increase in 2013, P. vivax malaria cases did not rise before spring 2014 (Figure 2).

In Sweden, 210 medical records from 21 hospitals were reviewed, representing $69.7 \%$ of the 307 notified cases in newly arrived Eritreans during 2014 and 2015. The cases had a mean age of 21 years (range: 2-61) and $154(72.9 \%)$ were males (Table 2). Twenty patients (9.5\%) fulfilled the World Health Organization (WHO) criteria for severe malaria [12] (19 with $P$. vivax and two with $P$. vivax and $P$. falciparum mixed infection); and two were admitted to intensive care unit (one with vivax malaria and impaired consciousness and one with vivax malaria and severe anaemia). The most common sign of severe illness was severe anaemia ( $n=12$ ) with (haemogloblin level of $37-66 \mathrm{~g} / \mathrm{L}$ (normal value: $117-164 \mathrm{~g} / \mathrm{L}$ ); and 20 patients with haemogloblin levels between 37 and $93 \mathrm{~g} / \mathrm{L}$ received blood transfusions. Haemogloblin levels were inversely correlated with symptom duration (Spearman $=-0.37$, $p<0.001$ ), and patients with severe malaria tended to have longer symptom duration $(p=0.087)$. Lower age was significantly associated with decreased haemogloblin levels (Spearman $=0.177, p=0.0053$ ), but not with symptom duration (Spearman $=0.01, p=0.82$ ), or severe malaria (Wilcoxon -Mann-Whitney test $p=0.9$ ). The proportion of $P$. vivax relapses after treatment in Sweden was $8.1 \%$.

Treatment for malaria along the route of travel to Sweden was reported in 105 (50\%) of cases in Sweden (data were missing for 55 patients) and median symptom duration before healthcare contact in Sweden was 3 days (range: 0-180 days) (Table 2). Patients reported a migration route starting in Eritrea and travelling through Ethiopia and/or Sudan, and then to 


\section{FIGURE 1}

Incidence of malaria cases per 1,000 Eritrean asylum applicants in different age groups, Germany and Sweden, 2013-2015

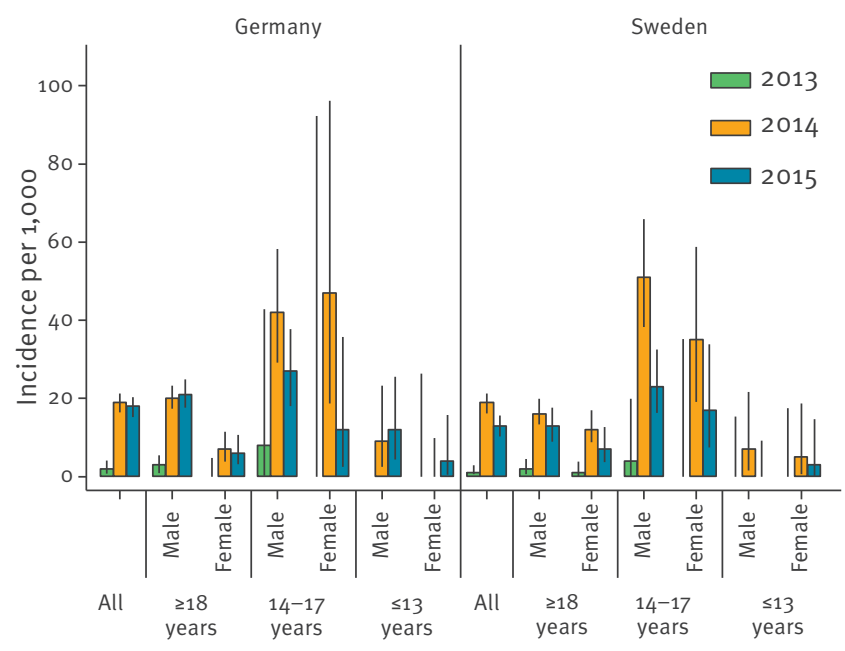

The black lines indicate the $95 \%$ confidence intervals.

Libya before crossing the Mediterranean Sea to Europe (Table 2). These countries were reported as country of infection in the national malaria statistics in Sweden and accounted for the overall increase in 2014 and 2015 (Figure 3); only 10 of the 205 P. vivax cases in 2014 had other countries of infection (India, Pakistan, Afghanistan, Tanzania, Somalia, Peru and Papua New Guinea). When comparing individual data for 209 medical records from 2014 and 2015 with those stated in the surveillance data, the countries of infection matched in $62(29.5 \%)$ patients, differed in 34 of 209 , and were missing in the medical records of 105 patients (50.5\%). Eight of 209 patients could not be identified in the national database. Hence, in 34 of the 96 patients with stated country of infection in both surveillance and medical record, the countries did not match.

\section{Switzerland}

Switzerland received between 6,920 and 9,965 annual Eritrean asylum applicants in 2014 to 2016 . The total number of malaria cases approximately doubled during this time period compared to the period 2011 to 2013 , and the increase was predominantly due to malaria in Eritreans (Table 1). This group represented 3 to 12 cases annually in 2011 to 2013 and 46 to 151 in the following 3 years. Malaria incidence was approximately 15 per 1,000 Eritreans in 2014 and 2015 but dropped to 8.8 in 2016, although 5,178 asylum applicants registered in the same year.

\section{The Netherlands}

The Netherlands received between 1,925 and 7,455 asylum applications from Eritreans in 2014 to 2016, in parallel with a marked increase in the total number of malaria cases represented by $P$. vivax, whereas for other malaria species, no increase was seen. The median age in the group of Eritreans with $P$. vivax malaria was 20 years in the period 2014 to 2016 and male sex was more common than female. In contrary to most other countries, the Netherlands reported incidence rates similar to 2014 and 2015 also during 2016 with an incidence rate of 23.9 (17.5-31.9).

\section{Norway}

Norway received approximately 3,000 Eritrean asylum applicants per year in the years 2013 to 2015. Despite similar numbers of asylum applications during these years, the increase in malaria cases did not occur until 2014. Analysis of malaria incidence rates revealed 4.0 (95\% Cl: 2.1-6.8), 18.4 (95\% Cl: 13.8-24.1) and 11.9 (95\% Cl: 8.3-16.5) per 1,000 Eritreans in 2013, 2014 and 2015, respectively. Data for 2016 as well as data on age and sex were not available.

\section{Denmark}

Denmark received increasing numbers of Eritrean asylum applications in 2014 ( $n=2,275)$ compared to previous years where maximum annual number was 85 . Malaria incidence was $14.5-17.0$ per 1,000 Eritreans in 2014 to 2015 and continuously high (43.1 per 1,000 but with wide $\mathrm{Cl}$ ) in 2016. Out of 74 cases during 2014 to 201650 were male and the median age during the same period was 24 years. However, only 255 Eritreans sought asylum in Denmark in 2016.

\section{United Kingdom}

The UK received 3,280 and 3,270 asylum applications from Eritrean citizens in 2014 and 2015 respectively. The UK was the country with the highest overall annual number of malaria cases, but the increase was not as pronounced, with 1,501 cases in 2013 and 1,586 cases in $2014(p=0.13)$. This increase was not significant, but country of birth was missing for a large proportion of cases (reported in 4,010/7,537 (53.2\%) of cases in 2011-2015). When malaria incidence malaria among Eritreans was calculated, it was lower compared to the other countries studied $(6.1,5.4$ and $10.0 / 1,000$ in the years 2014, 2015 and 2016) with low numbers of registered cases among Eritreans (20 per year in 2014 and 2016 and 13 in 2016). The majority of patients were male (18/20 in both 2015 and 2016), P. vivax was the dominating species among Eritreans and age median age in this group was 20 years in 2014 and 21 years in both 2015 and 2016.

\section{Discussion}

This analysis of European data on annual asylum seekers and imported malaria cases revealed a sudden and significant rise in malaria cases in seven European countries during 2014 and 2015. The increase was mainly explained by $P$. vivax cases in Eritreans. The seven countries accounted for $93 \%$ of applications from Eritrean asylum seekers in Europe. We found that the increase in malaria cases was not only due to a higher number of asylum applications compared to previous years; there was also a substantial increase in the proportion of Eritreans affected by the disease, 
Clinical characteristics in Eritreans with malaria extracted from medical records in Sweden and Germany, 2014-2015 $(\mathrm{n}=262)$

\begin{tabular}{|c|c|c|c|}
\hline Characteristics & $\begin{array}{c}\text { Sweden } \\
\text { (multicenter) } \\
\mathrm{N}=210\end{array}$ & $\begin{array}{c}\text { Germany } \\
\text { (Hamburg) } \\
\mathrm{N}=52\end{array}$ & $\mathrm{p}$ value \\
\hline Age in years, median (range) & $21(2-61)$ & $19(12-52)$ & 0.84 \\
\hline Proportion males & $154 / 210$ & $44 / 52$ & 0.11 \\
\hline \multicolumn{4}{|l|}{ Infection due to species of malaria } \\
\hline Plasmodium vivax & 186 & 52 & NA \\
\hline Plasmodium falciparum & 9 & o & NA \\
\hline Plasmodium ovale & 9 & o & NA \\
\hline Mixed Plasmodium vivax and Plasmodium falciparum & 6 & 0 & NA \\
\hline \multicolumn{4}{|l|}{ Migration route from Eritrea } \\
\hline Via Sudan and Libya & 68 & 21 & 0.08 \\
\hline Via Ethiopia, Sudan and Libya & 97 & 14 & NA \\
\hline Missing data & 45 & 17 & NA \\
\hline Migration duration in months, median (range) & $4(1-72)$ & $6(1-10)$ & 0.56 \\
\hline \multicolumn{4}{|l|}{ Malaria treatment during migration } \\
\hline Treated once & 80 & 18 & 0.002 \\
\hline Treated $2-6$ times & 25 & 20 & NA \\
\hline Missing data & 55 & 6 & NA \\
\hline \multicolumn{4}{|l|}{ Clinical symptoms and laboratory findings } \\
\hline Symptom duration at diagnosis in days, median (range) & $3(0-180)$ & $3(1-180)$ & 0.829 \\
\hline Haemogloblin g/L, median (range) (normal values 117-170) & $114(37-171)$ & $125(55-161)$ & 0.004 \\
\hline Platelet count number x 10\%/ $\mu$ l, median (range) ((normal values 150-400) & $105(5-289)$ & $118(23-380)$ & 0.52 \\
\hline Severe malaria according to WHO criteria & 20 & 1 & 0.07 \\
\hline Severe Plasmodium vivax & 18 & 1 & NA \\
\hline Severe mixed infection (Plasmodium falciparum and P. vivax) & 2 & 0 & NA \\
\hline Severe anaemia & 11 & 1 & NA \\
\hline Other criteria for severe malaria & 9 & 0 & NA \\
\hline Preventive anti-relapse treatment (primaquine) prescribed & 173 & 51 & 1.000 \\
\hline Relapse after treatment & 17 & 4 & 0.352 \\
\hline
\end{tabular}

WHO: World Health Organization; NA: no analysis performed.

especially among young male adults and adolescents. The patients reported migrating from Eritrea through Ethiopia and/or Sudan and Libya before arriving in Europe, and many had repeated febrile episodes on their migration route. The review of medical records in Germany and Sweden found a relatively high proportion of severe $P$. vivax malaria, predominantly characterised by severe anaemia, and more frequently in Sweden compared to Germany. The difference in proportion of severe cases is surprising and could imply that malaria diagnosis was delayed in Sweden, or because the data was collected in two different settings. Importantly, low haemogloblin levels were associated with longer symptom duration.

Our analysis of national surveillance data and medical records is consistent with previous reports of $P$. vivax clusters in Eritrean migrants in Europe in 2014
[4-6] as well as more recent national reports [7-9], and provides a more complete and detailed picture. The estimated mean incidence rate in the seven countries in the study increased from 2 malaria cases per 1,000 Eritrean asylum applications in 2013 to 18 cases per 1,000 in 2014. In 2016, although the number of Eritrean asylum applications remained high in some countries such as Germany, the number of malaria cases in this group dropped markedly, suggesting either changes in the epidemiology of malaria along the route of migration or a possible change in migration routes. We estimated that there were at least 1,500 malaria cases in Europe during 2014 and 2015 that can be attributed to newly arrived Eritreans. However, the number of malaria cases in Eritrean migrants in Europe during this period is likely to be even higher, as an unknown number of arriving Eritreans might have sought medical care in countries along their migration route, as reports 
Weekly number of Eritreans seeking asylum and Plasmodium vivax cases reported in Sweden, 2011-2016

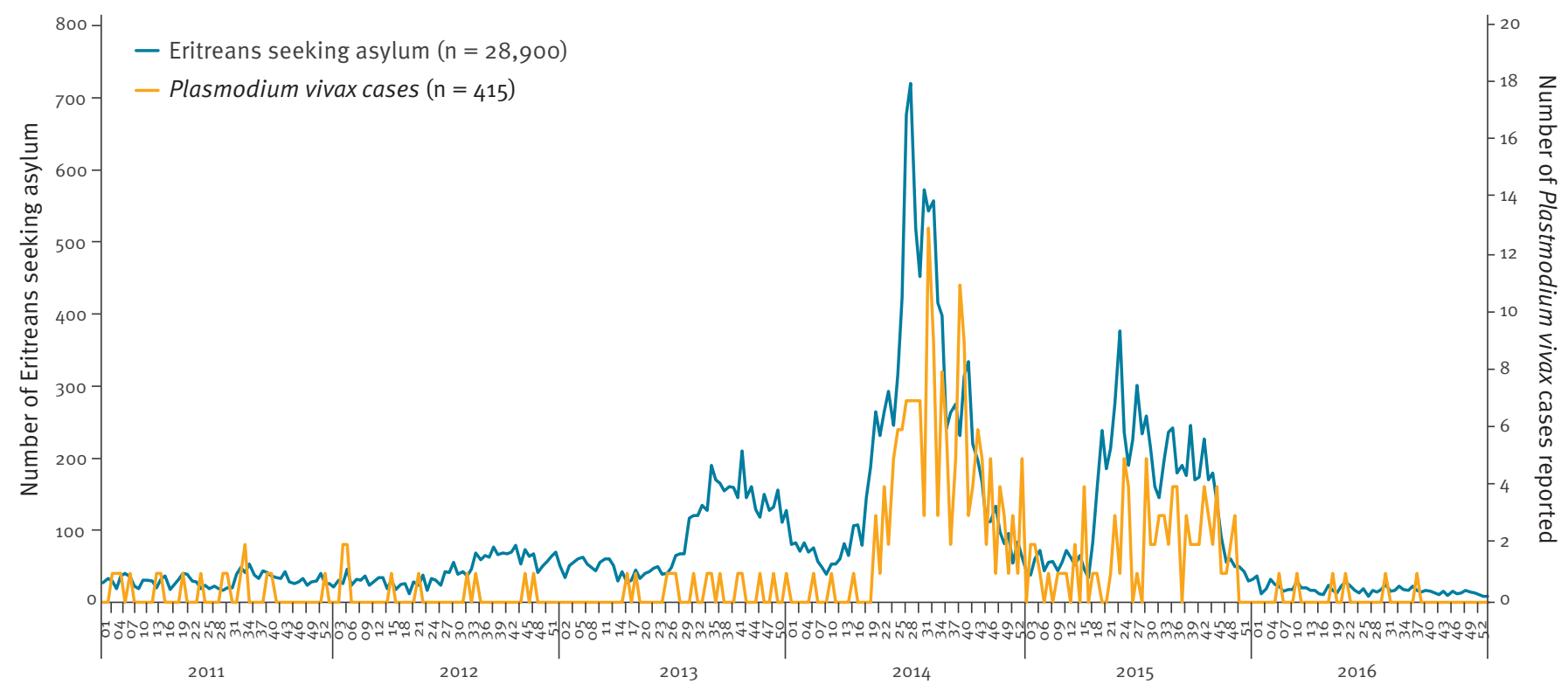

Years/week number

from Italy suggest [13]. Part of the increase might be due to greater awareness and increased testing by clinicians or microbiological laboratories in parallel with the greater number of cases that were diagnosed from 2014 onwards. A limitation of this report is that countries were selected based on registered asylum applications from Eritreans and furthermore, detailed data was available only for Germany and Sweden. Nonetheless, the seven EU/EFTA countries receiving $93 \%$ of Eritrean asylum applicants contributed data.

Patients in Hamburg (Germany) and Sweden reported migrating from Eritrea through Ethiopia and/or Sudan and Libya before arriving in Europe. According to the WHO World Malaria Report, P. vivax accounted for $26 \%$ of clinical malaria cases in Eritrea, $41 \%$ in Ethiopia and $5 \%$ in Sudan in 2014 [14]. Clusters of $P$. vivax malaria cases in Eritreans have previously been reported in Israel and Jordan [15-17]. To our knowledge, there have been no reports published on epidemics or increased $P$. vivax incidence in Eritrea, Ethiopia or Sudan during 2014 and 2015, but rather a decline in transmission has been observed [14]. Libya is considered to be malariafree, although recent case reports raise suspicion of autochthonous $P$. falciparum and $P$. vivax transmission in the country [18]. The high incidence in Eritrean asylum applicants (higher than in Eritrea) thus suggests some high-level local malaria transmission along their route of migration, possibly in eastern Ethiopia where $P$. vivax transmission is reported to be high [1].

Malaria was predominantly diagnosed in male teenagers with 1 case in 20 male asylum applicants. Lack of acquired immunity in adolescents who have grown up in Eritrea where malaria transmission is low [14] may have contributed to a particularly high level of vulnerability in this group to parasite exposure during migration. Noteworthy, many patients reported that they were already suffering from malaria attacks during migration, and treatment of $P$. vivax, not including radical cure of hypnozoites, may have resulted in relapsing infections. Indeed, analysis of weekly data in Sweden revealed that the $P$. vivax cases were predicted by the number of asylum applications from Eritreans 5 weeks prior to the actual malaria notifications, which may reflect relapses rather than primary infections, in particular considering that most patients had left malaria-endemic areas several months earlier. Stress and generally impaired health status of the host during and immediately after the migration process could be possible contributions to relapses of malaria [19]. Our findings highlight the need to focus and report on active malaria transmission on migration routes and to promote local interventions. Countries receiving migrants from Africa need to be aware that the epidemiology of imported malaria may change rapidly and that relapses of $P$. vivax can occur several months after arrival in Europe.

The geographical patterns of imported malaria in Europe were recently modelled using national statistics [20]. Despite covering the same time period, modelling from aggregated data did not seem to capture the high number of $P$. vivax cases in a particular migrant group. Indeed, using only reported country of infection (especially only one country) has limitations as reflected by our comparison: clinical medical records and notification data showed coherence of the 


\section{FIGURE 3}

Number of (A) malaria, (B) Plasmodium vivax and (C) Plasmodium falciparum cases diagnosed in Sweden by reported possible country of infection, 2005-2016

A. Malaria, all species

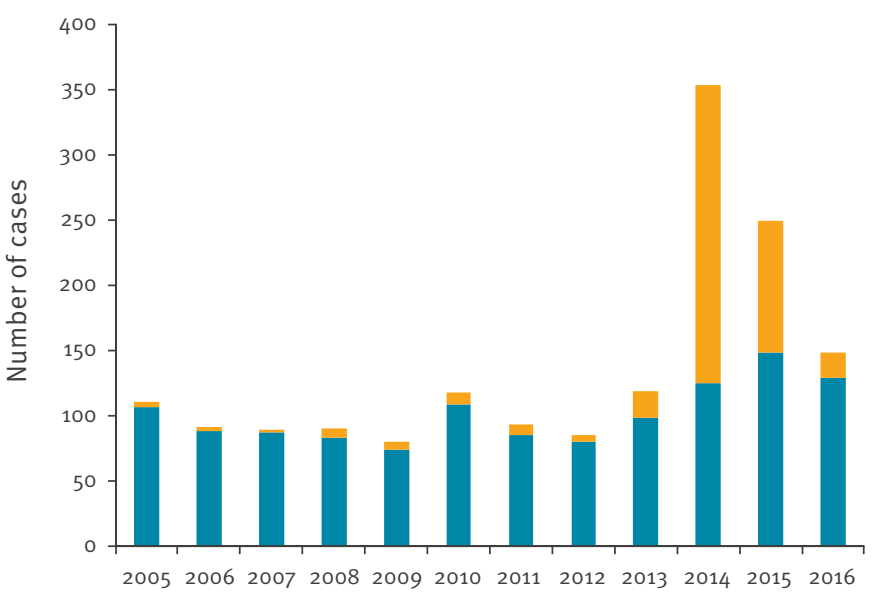

C. P. falciparum

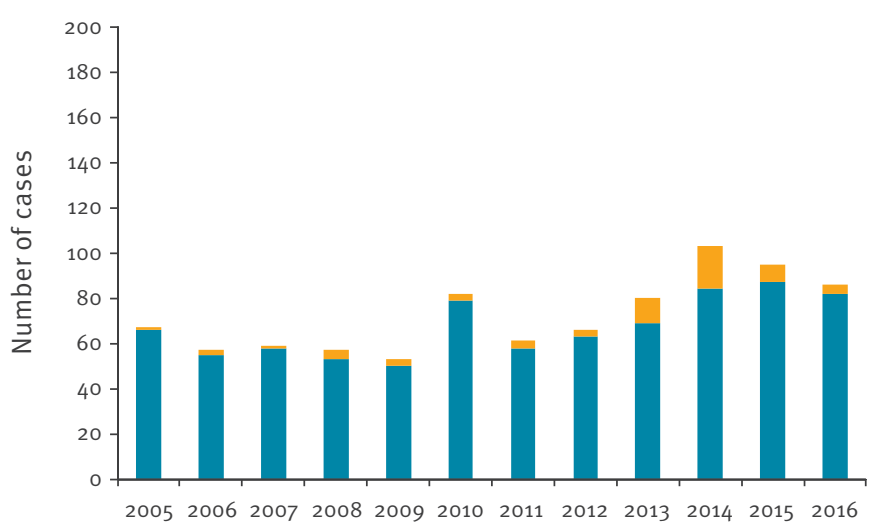

B. P. vivax

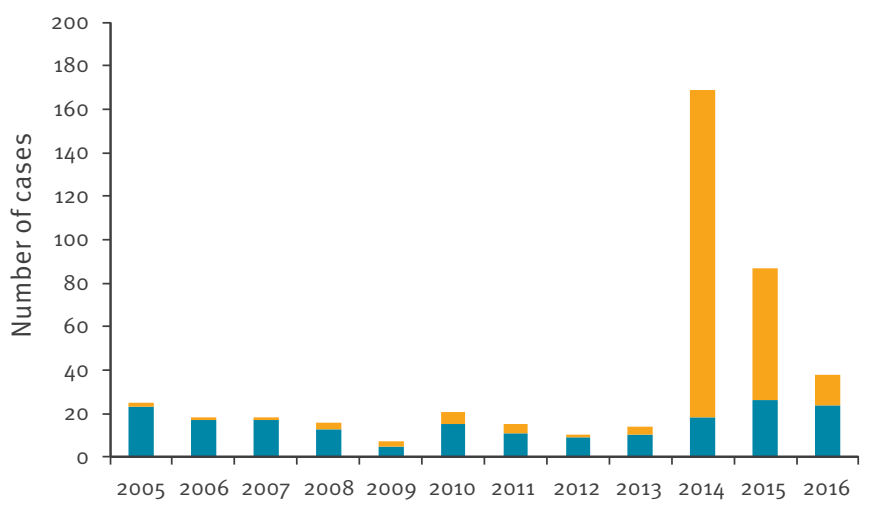

Eritrea, Ethiopia and/or Sudan

P: Plasmodium.

Data based on patient-reported travel route and notifications in the medical record.

country of infection in only $35 \%$ of patients (reflecting limitations both in medical recordings and notification data). If this data can be collected, it could result in better risk assessment and more rapid detection of infections, in particular among vulnerable migrant groups.

Europe was declared malaria-free by WHO in 2016 [21]. Nonetheless, Anopheles mosquitoes with competence in malaria transmission are present in large parts of Europe [22]. A proportion of migrants in Sweden and Germany did not attend treatment follow-up and had unclear compliance regarding primaquine. As relapse frequency after treatment is $7-8 \%$ this might possibly be a public health issue. The risk of secondary cases in some parts of Europe thus exists but is relatively small; public health professionals need to be aware of the entomology data and which mosquito species are present in their area of responsibility and should develop strategies to successful eradication treatment of $P$. vivax $[1,22]$.

Our review of medical records showed that severe malaria cases and repeated episodes were common. Haemogloblin levels correlated with symptom duration and a high proportion of severe anaemia requiring blood transfusions in Sweden is believed to be a result of prolonged symptoms and/or repeated episodes which are factors known to contribute to vivax anaemia [23]. Healthcare and general conditions are expected to be poor for refugees during migration, and displaced populations have been reported to be at increased risk of malaria [24]. Any febrile patients (including refugees) who have travelled through or arrived from 
malaria-endemic areas must be thoroughly investigated, including a blood test for malaria. Clinicians and healthcare workers need to be aware of potentially severe symptoms. Screening refugees or asylum seekers arriving from malaria endemic areas could contribute to a more rapid diagnosis and treatment, and migrant populations from other parts of Africa or the Indian subcontinent could be considered. Irrespective of this, it is important to ensure migrants' access to healthcare, especially for potentially severe diseases, on the basis of the international human rights law regarding migrants' right to health [25].

In conclusion, we report a remarkably high incidence of vivax malaria among newly arrived Eritrean asylum seekers in Europe during 2014 and 2015. Policy makers as well as individual healthcare workers need to be prepared for rapid changes in the patterns of imported malaria, and possibly other infectious diseases, in migrants and particularly in refugees and asylum seekers who may have undertaken long journeys through several countries to Europe.

\section{Acknowledgements}

We wish to thank everyone involved in the collection of data in the countries concerned, from hospital units, laboratories and Public Health Agencies, as well as Valerie Smith and Parisha Katwa from Public Health England Malaria Reference Laboratory and Travel and Migrant Health Section respectively for providing malaria surveillance data for the United Kingdom.

\section{Conflict of interest}

None declared.

\section{Authors' contributions}

Conceived the idea of the report: KISo, TR, AF, AT. Extracted and analysed clinical data: AW, TR, RK, JoDo. Extracted and analysed malaria surveillance data: EY, SVB, JaDu, BDG, JF, NG, KISt, FS, LSV, AT. Performed statistical analyses: UH. Wrote the paper: KISo, TR, AF. All authors revised the manuscript and approved the final version.

\section{References}

1. European Centre for Disease Prevention and Control (ECDC). Risk of importation and spread of malaria and other vectorborne diseases associated with the arrival of migrants to the EU. Stockholm: ECDC; 2015. Available from: https:// ecdc.europa.eu/sites/portal/files/media/en/publications/ Publications/risk-malaria-vector-borne-diseases-associatedwith-migrants-october-2015.pdf

2. Broderick C, Nadjm B, Smith V, Blaze M, Checkley A, Chiodini $\mathrm{PL}$, et al. Clinical, geographical, and temporal risk factors associated with presentation and outcome of vivax malaria imported into the United Kingdom over 27 years: observational study. BMJ. 2015;350(apr16 13):h1703. https://doi.org/10.1136/ bmj.h1703 PMID: 25882309

3. Gautret P, Cramer JP, Field V, Caumes E, Jensenius M, Gkrania-Klotsas E, et al. Infectious diseases among travellers and migrants in Europe, EuroTravNet 2010. Euro Surveill. 2012;17(26):20205. PMID: 22790534

4. Sonden K, Castro E, Törnnberg L, Stenstrom C, Tegnell A, Farnert A. High incidence of Plasmodium vivax malaria in newly arrived Eritrean refugees in Sweden since May 2014. Euro Surveill. 2014;19(35):20890. PMID: 25210980

5. Roggelin L, Tappe D, Noack B, Addo MM, Tannich E, Rothe C. Sharp increase of imported Plasmodium vivax malaria seen in migrants from Eritrea in Hamburg, Germany. Malar J. 2016;15(1):325. https://doi.org/10.1186/s12936-016-1366-7 PMID: 27316351

6. Norwegian Institute of Public Health (Folkehelseinstituttet). Malaria - veileder for helsepersonell. [Malaria - supervisor for health professionals]. Oslo: Folkehelseinstituttet. [Accessed 10 Feb 2016]. Norwegian. Available from: https:// www.fhi.no/nettpub/smittevernveilederen/sykdommer-a-a/ malaria---veileder-for-helsepersone/

7. de Gier B, Suryapranata FS, Croughs M, van Genderen PJ, Keuter $M$, Visser LG, et al. Increase in imported malaria in the Netherlands in asylum seekers and VFR travellers. Malar J. 2017;16(1):6o. https://doi.org/10.1186/s12936-017-1711-5 PMID: 28148300

8. Statens Serum Institut (SSI). Malaria 2014. Updated recommendations for malaria prophylaxis MERS-CoV outbreak in South Korea. EPI-News. 2015;25. Available from: http:// www.ssi.dk/English/News/EPI-NEWS/2015/No\%2025\%20-\%20 2015.aspx

9. Eperon G, Durieux-Paillard S, Mauris A, Chappuis F, Gysin N. Malaria cases in Switzerland from 2005 to 2015 and recent rise of imported Plasmodium vivax malaria. Swiss Med Wkly. 2017;147:W14510. PMID: 29063526

10. Eurostat. Asylum statistics. [Accessed 5 Apr 2016]. Available from: http://ec.europa.eu/eurostat/statistics-explained/index. php/Asylum_statistics

11. McFadden D. Conditional logit analysis of qualitative choice behavior. In: Zarembka P, editor. Frontiers in econometrics. New York: Academic Press; 1974. p. 104-142.

12. World Health Organization (WHO). Severe falciparum malaria. World Health Organization, Communicable Diseases Cluster. Trans R Soc Trop Med Hyg. 2000;94(Suppl 1):S1-90. PMID: 11103309

13. Grande R, di Gregorio A, Gismondo MR, Galli M, Antinori S. Rise in Plasmodium vivax malaria in a referral university hospital in Northern Italy. Abstracts of the gth European Congress on Tropical Medicine and International Health; 2015 Sep 6-10; Basel, Switzerland. Tropical Medicine and International Health; 2015.

14. World Health Organization (WHO). World Malaria Report 2016. Geneva: WHO; 2016. Available from: http://www.who.int/ malaria/publications/world_malaria_report_2016/en/

15. Saidel-Odes L, Riesenberg K, Schlaeffer F, Smolyakov R, Kafka M, Borer A. Eritrean and Sudanese migrants presenting with malaria in Israel. Travel Med Infect Dis. 2011;9(6):303-5. https://doi.org/10.1016/j.tmaid.2011.09.003 PMID: 22037052

16. Kopel E, Schwartz E, Amitai Z, Volovik I. Relapsing vivax malaria cluster in Eritrean refugees, Israel, June 2010. Euro Surveill. 2010;15(26):19601. PMID: 20619133

17. Jamain HM, Abu Shaqra QA, Kanani KA. Epidemiological pattern of imported malaria in Jordan from 2007 to 2011. Trop Biomed. 2013;30(4):591-5. PMID: 24522127

18. Ahmed MO, Daw MA. Mapping the travel route of African refugees who traverse Libya to determine public health implications for Libya and the North-African region. Travel Med Infect Dis. 2016;14(2):162-4. https://doi.org/10.1016/j. tmaid.2015.12.007 PMID: 26787307

19. Shanks GD, White NJ. The activation of vivax malaria hypnozoites by infectious diseases. Lancet Infect Dis. 2013;13(10):900-6. https://doi.org/10.1016/S14733099(13)70095-1 PMID: 23809889

20. Tatem AJ, Jia P, Ordanovich D, Falkner M, Huang Z, Howes R, et al. The geography of imported malaria to non-endemic countries: a meta-analysis of nationally reported statistics. Lancet Infect Dis. 2017;17(1):98-107. https://doi.org/10.1016/ S1473-3099(16)30326-7 PMID: 27777030

21. World Health Organization Regional Office for Europe (WHO/ Europe). History of malaria elimination in the European region. Copenhagen: WHO/Europe; 2016. Available from: http://www. euro.who.int/_data/assets/pdf_file/0003/307272/Facsheetmalaria-elimination.pdf

22. Piperaki ET, Daikos GL. Malaria in Europe: emerging threat or minor nuisance? Clin Microbiol Infect. 2016;22(6):487-93. https://doi.org/10.1016/j.cmi.2016.04.023 PMID: 27172807

23. Douglas NM, Anstey NM, Buffet PA, Poespoprodjo JR, Yeo TW, White NJ, et al. The anaemia of Plasmodium vivax malaria. Malar J. 2012;11(1):135. https://doi.org/10.1186/1475-2875-11135 PMID: 22540175

24. Charchuk R, Paul MK, Claude KM, Houston S, Hawkes MT. Burden of malaria is higher among children in an internal displacement camp compared to a neighbouring village in the 
Democratic Republic of the Congo. Malar J. 2016;15(1):431.

https://doi.org/10.1186/s12936-016-1479-Z PMID: 27557931

25. Office of the United Nation High Commission for Human Rights (OHCHR) and World Health Organization (WHO). The right to health. Geneva: OHCHR and WHO; 2008. Available from: http:// www.ohchr.org/Documents/Publications/Factsheet31.pdf

\section{License and copyright}

This is an open-access article distributed under the terms of the Creative Commons Attribution (CC BY 4.0) Licence. You may share and adapt the material, but must give appropriate credit to the source, provide a link to the licence, and indicate if changes were made.

This article is copyright of the authors or their affiliated institutions, 2019. 